\title{
Interferon gamma (IFN- $\gamma$ )-mediated inflammation and the kynurenine pathway in relation to risk of hip fractures: the Hordaland Health Study
}

\author{
E. M. Apalset • C. G. Gjesdal • P. M. Ueland • J. Øyen • \\ K. Meyer • Ø. Midttun • G. E. Eide • G. S. Tell
}

Received: 5 March 2014 / Accepted: 14 April 2014 /Published online: 10 May 2014

(C) The Author(s) 2014. This article is published with open access at Springerlink.com

\begin{abstract}
Summary The cytokine interferon gamma (IFN- $\gamma$ ) stimulates neopterin release and tryptophan degradation into kynurenines through the kynurenine pathway. High levels of neopterin were associated with increased hip fracture risk, as were some of the kynurenines, suggesting a role of IFN- $\gamma$ mediated inflammation in the processes leading to hip fracture.

Introduction Low-grade systemic inflammation has been associated with bone loss and risk of fractures. Interferon gamma (IFN- $\gamma$ ) initiates macrophage release of neopterin and also stimulates degradation of tryptophan along the kynurenine
\end{abstract}

E. M. Apalset $(\bowtie) \cdot$ J. Øyen $\cdot$ G. E. Eide $\cdot$ G. S. Tell

Department of Global Public Health and Primary Care, University of

Bergen, Kalfarveien 31, 5018 Bergen, Norway

e-mail: ellen.apalset@igs.uib.no

J. Øyen

e-mail: Jannike.Oyen@igs.uib.no

G. E. Eide

e-mail: Geir.Egil.Eide@Helse-Bergen.no

G. S. Tell

e-mail: Grethe.Tell@igs.uib.no

E. M. Apalset • C. G. Gjesdal • J. Øyen

Department of Rheumatology, Haukeland University Hospital,

Bergen, Norway

C. G. Gjesdal

e-mail: clara.gjesdal@helse-bergen.no

C. G. Gjesdal • P. M. Ueland

Department of Clinical Science, University of Bergen, Bergen, Norway

P. M. Ueland

e-mail: per.ueland@ikb.uib.no pathway as part of cell-mediated immune activation. Plasma neopterin and the kynurenine/tryptophan ratio (KTR) are thus markers of IFN- $\gamma$-mediated inflammation. Risk of hip fracture was investigated in relation to markers of inflammation and metabolites in the kynurenine pathway (kynurenines).

Methods Participants ( 71 to 74 years, $N=3,311$ ) in the community-based Hordaland Health Study (HUSK) were followed for hip fractures from enrolment (1998-2000) until 31 December 2009. Plasma C-reactive protein (CRP), neopterin, KTR, and six kynurenines were investigated as predictors of hip fracture, using Cox proportional hazards regression analyses.

P. M. Ueland

Laboratory of Clinical Biochemistry, Haukeland University Hospital, Bergen, Norway

K. Meyer $\bullet \varnothing$. Midttun

Bevital A/S, Laboratoriebygget, Bergen, Norway

K. Meyer

e-mail: klaus.meyer@farm.uib.no

Ø. Midttun

e-mail: Bjorn.Midttun@k2.uib.no

G. E. Eide

Centre for Clinical Research, Haukeland University Hospital, Bergen, Norway 
Results A hazard ratio (HR) of 1.9 (95\% confidence interval (CI) 1.3-2.7) for hip fracture was found in the highest compared to the lowest quartile of neopterin ( $p$ trend across quartiles $<0.001$ ). CRP and KTR were not related to hip fracture risk. Among the kynurenines, a higher risk of fracture was found in the highest compared to the lowest quartiles of anthranilic acid and 3-hydroxykynurenine. For subjects in the highest quartiles of neopterin, CRP, and KTR compared to those in no top quartiles, HR was 2.5 (95\% CI 1.6-4.0).

Conclusions This may indicate a role for low-grade immune activation in the pathogenic processes leading to hip fracture.

Keywords Hip fracture $\cdot$ Inflammation $\cdot$ Kynurenine pathway $\cdot$ Neopterin $\cdot$ Osteoimmunology $\cdot$ Osteoporosis

\section{Introduction}

Patients with inflammatory diseases are known to have higher risk of osteoporosis and fractures [1], and even low-grade subclinical systemic inflammation has been associated with low bone mineral density (BMD) [2]. High serum levels of proinflammatory cytokines, cytokine-soluble receptors [3, 4], and C-reactive protein (CRP) [5-9] have been associated with increased risk of fractures, although the findings are ambiguous for some of the inflammatory markers [3, 4].

The immune system influences differentiation and activity of bone cells within the bone microenvironment [1]. CRP is an acute phase reactant produced in response to cytokine release during inflammation, and high-sensitivity (hs) CRP allows assessment of low-grade inflammation. Interferon gamma (IFN- $\gamma$ ) is a major stimulator of cell-mediated immune activation [10] and differentiation of T cells and macrophages. In vitro and animal studies indicate a dual effect of IFN- $\gamma$ on bone. In normal bone remodeling, IFN- $\gamma$ may improve bone mass [11] and decrease bone degradation by blunting osteoclast formation [1]. In mouse models of inflammatory states, IFN- $\gamma$ enhances bone degradation e.g., via stimulation of $T$ cell secretion of the receptor activator of NF- $\mathrm{KB}$ ligand (RANKL) and tumor necrosis factor $\alpha$ [12]. In humans, IFN- $\gamma$ has been used to increase bone resorption in pathologically dense bone tissue (osteopetrosis) [1]. Results from a few [13-15], but not all [16] studies have indicated an association between IFN- $\gamma$ or gene variants influencing IFN- $\gamma$ level, with osteoporosis and fracture risk.

In a state of immune activation, IFN- $\gamma$ stimulates macrophages to release neopterin [17], which due to its stability in body fluids is used as an index of IFN- $\gamma$-mediated inflammation [10] and for the assessment of disease activity in several conditions [10]. Further, IFN- $\gamma$ stimulates the indoleamine dioxygenase (IDO) enzyme [18], initiating degradation of the essential amino acid tryptophan through the kynurenine pathway into metabolically active compounds known as kynurenines (Fig. 1). IDO and the kynurenines are increasingly recognized as important regulators of the immune system, e.g., by modulating the function of regulatory T cells [18, 19]. Some kynurenines are powerful regulators of oxidative stress as well, having both pro- and anti-oxidant abilities [20].

Kynurenine is the initial degradation product of tryptophan through the kynurenine pathway, and the kynurenine/ tryptophan ratio (KTR) is a marker of IDO activity and cellmediated inflammation [18]. Increased KTR has been related to neurological and mental conditions [21], as well as to cardiovascular [22] and renal disease [23]. A possible relation between neopterin or the kynurenines and risk of hip fractures has not previously been reported.

We have earlier reported inverse associations between BMD and IFN- $\gamma$-mediated inflammation and positive associations with some metabolites of the kynurenine pathway [24]. The aim of the present study was to extend our previous findings by further examining IFN- $\gamma$-associated inflammation markers and kynurenines, in addition to hs-CRP, as predictors of hip fracture.

\section{Materials and methods}

\section{Subjects}

The community-based Hordaland Health Study (HUSK) was conducted in the city of Bergen and three neighboring municipalities, and cohort inclusion took place from April 1998 to June 1999. Subjects born during 1925-27 who had previously participated in the Hordaland Homocysteine Study 1992-93 were invited $(N=4,338)$. Of these, 3,341 met for the study and answered questionnaires. Blood samples were analyzed from 3,311 participants (76.3\% of those invited). The Regional Committee for Medical Research Ethics and the Norwegian Data Inspectorate approved the study protocol, and all participants signed an informed consent. The study was performed according to the principles of the Declaration of Helsinki of the World Medical Association.

\section{Blood samples}

Non-fasting blood samples were drawn and stored in EDTAcontaining tubes, which were chilled within 15-30 min and then centrifuged. Unfrozen plasma samples were transported to the laboratory, usually arriving within 1 day, always within 4 days. The samples were frozen at $-80^{\circ} \mathrm{C}$ and stored for up to 13 years before analysis [25]. Plasma analyses of tryptophan and the kynurenines (kynurenine, kynurenic acid, anthranilic acid, 3-hydroxykynurenine, xanthurenic acid, and 3hydroxyanthranilic acid), neopterin, and cotinine (a nicotine metabolite used as a biomarker of recent nicotine exposure) were performed using liquid chromatography-tandem mass 
Fig. 1 The kynurenine pathway of tryptophan metabolism. Degradation of the essential amino acid tryptophan through the kynurenine pathway is initiated by either indoleamine 2,3-dioxygenase or by tryptophan dioxygenase (TDO). TDO is primarily found in the liver and is induced by tryptophan and corticosteroids, whereas IDO is an ubiquitous enzyme induced by cytokines. $A M O$ anthranilate monooxygenase, $K A T$ kynurenine aminotransferase, $K M O$ kynurenine monooxygenase, $K Y N U$ kynureninase

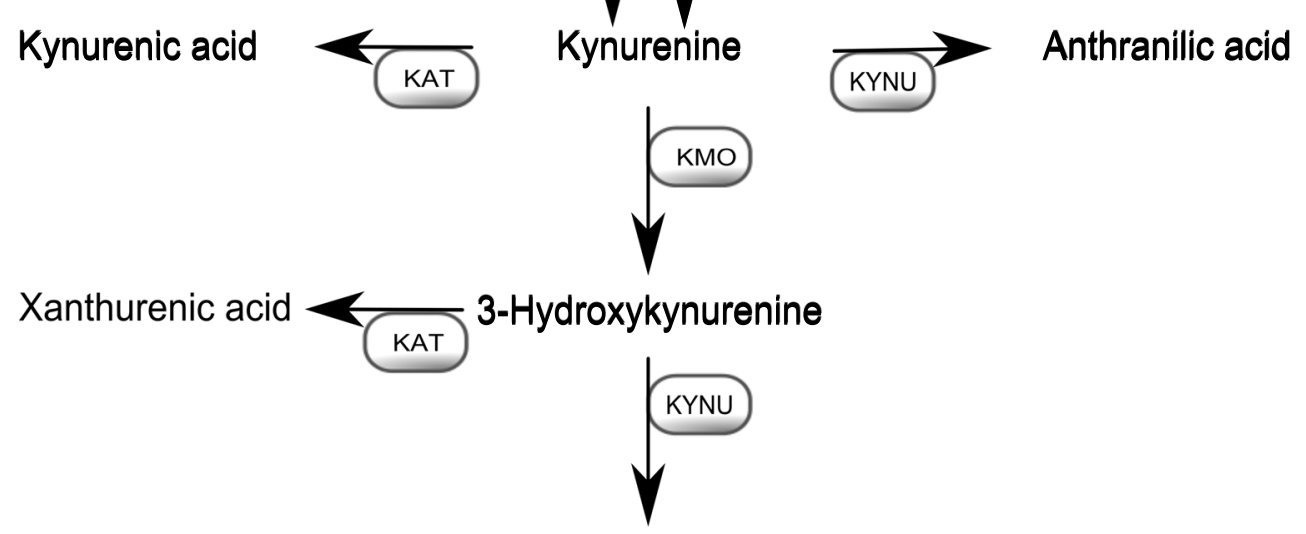

3-Hydroxyanthranilic acid

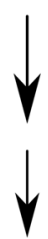

Nicotinamide containing nucleotides spectrometry (LC/MS/MS) at Bevital A/S (www.bevital.no/), Bergen, Norway [26]. Studies of stability and deterioration kinetics indicate that the studied biomarkers are stable under these conditions [27, 28].

Sensitive C-reactive protein EDTA plasma levels were determined at Bevital A/S by a novel immuno-assay based on matrix-assisted laser desorption/ionization time-of-flight mass spectrometry (MALDI-TOF MS).

\section{Hip fractures}

A hip fracture was defined as the first fracture of the proximal femur occurring during the observation period between baseline and 31 December 2009. Information on hip fractures was obtained from the hospitals serving Hordaland County, using a computerized search of discharge diagnosis records. Only hip fractures confirmed by a concurrent code of an adequate surgical procedure code were included, as previously described [29] and validated [30]. The discharge diagnoses used to classify a hip fracture were according to the International Classification of Diseases, Ninth Revision (ICD-9): 820 820.9 and Tenth Revision (ICD-10): S720-S722. Surgical treatments for each hospital stay were coded according to the Norwegian Classification of Surgical Procedures (version 2, 1989 and 3, 1995) and later the Nordic Medico-Statistical
Committee (NOMESCO) Classification of Surgical Procedures (version 1, 1999- version 3, 2004). The Norwegian Population Register provided information on time of death. Follow-up time was from enrolment until first hip fracture, death or 31 December 2009.

\section{Additional data}

Self-administered questionnaires provided information on health status, use of medication, sociodemographic data, and lifestyle factors. Use of disease-modifying anti-rheumatic drugs (DMARDs) was included in some of the analyses as a marker of inflammatory rheumatic disease. Reported use of DMARDSs included methotrexate, sulfasalazine, hydroxychloroquine, cyclosporine, auranofin, and penicillamine. Use of non-steroidal anti-inflammatory drugs (NSAIDs) was included in supplementary analyses to study any effect of these medications on the relation between inflammatory markers and hip fractures.

Height and weight were measured in light clothing, and body mass index (BMI; $\mathrm{kg} / \mathrm{m}^{2}$ ) calculated. BMD was measured by dual X-ray densitometer (EXPERT-XL; Lunar Company Inc, Madison, WI, USA, software version 1.72 and 1.90) in a subgroup of 2,221 participants as described earlier [24]. 
Statistical analyses

Distribution of continuous variables is reported as means and standard deviations (SD) for normally distributed variables, or medians and interquartile range for skewed distributions. Counts (percentages) are reported for categorical variables. Subjects with and without later hip fractures were compared within each sex, using the independent $t$ tests for continuous variables and the exact chi-square test for categorical outcomes.

Nicotine exposure (cotinine) was categorized into no, light, or heavy exposure for the baseline characteristics table, but cotinine was used as a continuous variable in the analyses. Use of corticosteroids, DMARDs, and NSAIDs was dichotomized into present use or no use. Renal function was estimated by glomerular filtration rate (eGFR) using the Modification of Diet in Renal Disease (MDRD) formula [31] and was dichotomized according to normal $(60 \mathrm{~mL} / \mathrm{min}$ or above) or reduced (below $60 \mathrm{~mL} / \mathrm{min}$ ) renal function.

Correlations between CRP, neopterin and KTR in the whole cohort were assessed by Spearman's rho (rs).

Cox proportional hazards model was used to estimate the associations between serum neopterin, KTR, tryptophan, and kynurenines (continuous and categorized into quartiles) and risk of subsequent hip fracture. Analyses using quartiles of the inflammatory markers and kynurenines are reported, as well as $p$ for trend across quartiles. Multicollinearity between covariates and interactions between covariates and time were tested. The multivariable model includes sex, BMI, cotinine, and eGFR.

A composite measure was constructed by combining those being in the highest quartile of all the three inflammatory markers (CRP, neopterin, and KTR), the highest quartile of two (CRP and neopterin, or CRP and KTR), one or none, and the risk of hip fracture was examined using Cox regression analyses.

Significance level of 0.05 was chosen for all statistical tests. The statistical package SPSS (version 18 for Windows, Chicago, IL, USA) was used. Venn diagram was created using Google (https://developers.google.com/chart/image/docs/ chart_wizard).

\section{Results}

Follow-up data and baseline characteristics

Median follow-up time was 10.8 years (range $0.01-11.7$ ), and a hip fracture during follow-up was recorded among 277 $(8.4 \%)$ of the participants. Baseline characteristics are shown and compared according to hip fracture status within each sex in Table 1. No differences in factors related to health or lifestyle were found among men, but those later suffering a hip fracture had higher neopterin and anthranilic acid levels.
Women with a hip fracture during follow-up had lower baseline BMI and a higher exposure to nicotine. No significant differences in inflammation markers or kynurenines were found among women with and without a later hip fracture.

\section{Correlations}

A positive correlation was found between CRP and neopterin $\left(r_{s}=0.19, p<0.001\right), \mathrm{CRP}$ and KTR $\left(r_{s}=0.22, p<0.001\right)$, and neopterin and KTR $\left(r_{s}=0.52, p<0.001\right)$.

Inflammation markers, kynurenines, and risk of hip fracture

Cox proportional hazards regression analyses of risk of hip fractures were performed according to quartiles of CRP, neopterin, KTR, tryptophan, and kynurenines as shown in Table 2. A statistically significant prediction of hip fracture was found for neopterin and tryptophan after adjustment for sex. In the fully adjusted model (adjustment for sex, BMI, cotinine, and eGFR), a significant higher risk of hip fracture was found in the highest compared to the lowest quartiles of neopterin, anthranilic acid, and 3-hydroxykynurenine, with a significant trend across quartiles. The estimates were mostly unchanged after additional adjustment for use of corticosteroids and DMARDs, and there were no major changes after adjusting for use of NSAIDs. Levels of CRP and KTR were not associated with risk of hip fracture.

Additional analyses for anthranilic acid and 3hydroxykynurenine as continuous variables in relation to risk of hip fracture were done. Anthranilic acid was not significantly associated with hip fracture in analysis adjusting for sex only $(p=0.060)$, but significantly associated in the model adjusted for sex, BMI, cotinine, and eGFR $(p=0.003)$. A statistically significant association was also found between 3-hydroxykynurenine and risk of hip fracture $(p=0.033$ adjusted for sex, $p=0.001$ in the multiple adjusted model).

Cox proportional hazards regression analyses were also performed for risk of hip fracture in relation to the inflammatory markers and the kynurenines with additional adjustment for BMD among the 2,221 participants with BMD measurement, but this did not materially change the estimates.

Cox regression analyses were performed for men and women combined. However, an interaction between sex and neopterin was found for risk of hip fracture ( $p$ interaction= 0.021 ), with hazard ratio (HR) 3.23 (95\% confidence interval (CI) 1.69-6.19) for men in the highest compared to the lowest neopterin quartile ( $p$ trend across quartiles $<0.001$ ), and HR 1.48 (CI 0.99-2.22) among women ( $p$ trend $=0.069$ ). No interaction was found between sex and CRP, KTR, or kynurenines in relation to risk of hip fracture.

Subjects in the highest quartile (Q4) of all three inflammatory markers (CRP, neopterin, and KTR) ( $n=171$, constituting $5 \%$ of the cohort) had a higher risk of hip fracture compared 
Table 1 Baseline characteristics 1998-99 in 3,311 women and men (71-74 years old), stratified by hip fracture during follow-up. The Hordaland Health Study

\begin{tabular}{|c|c|c|c|c|c|c|}
\hline & \multicolumn{3}{|l|}{ Men } & \multicolumn{3}{|l|}{ Women } \\
\hline & $\begin{array}{l}\text { No hip fracture } \\
(n=1,369)^{\mathrm{a}}\end{array}$ & $\begin{array}{l}\text { Hip fracture } \\
(n=86)^{\mathrm{a}}\end{array}$ & $p$ value $^{\mathrm{b}}$ & $\begin{array}{l}\text { No hip fracture } \\
(n=1,665)^{\mathrm{a}}\end{array}$ & $\begin{array}{l}\text { Hip fracture } \\
(n=191)^{\mathrm{a}}\end{array}$ & $p$ value $^{\mathrm{b}}$ \\
\hline BMI, mean (SD) & $26.0(3.2)$ & $25.8(3.5)$ & 0.556 & $26.4(4.4)$ & $24.8(4.2)$ & 0.001 \\
\hline eGFR below $60 \mathrm{~mL} / \mathrm{min}, n(\%)$ & $273(20.0)$ & $19(22.1)$ & 0.677 & $928(55.7)$ & $92(48.2)$ & 0.055 \\
\hline Current use of corticosteroids, $n(\%)$ & $22(1.6)$ & $3(3.5)$ & 0.180 & $34(2.0)$ & $7(3.7)$ & 0.185 \\
\hline Current use of DMARD, $n(\%)$ & $11(0.8)$ & $2(2.3)$ & 0.177 & $21(1.3)$ & $5(2.6)$ & 0.179 \\
\hline Current use of NSAID, $n(\%)$ & $35(2.6)$ & $2(2.3)$ & 0.999 & $111(6.7)$ & $15(7.9)$ & 0.543 \\
\hline Current use of estrogen, $n(\%)$ & NA & NA & & $176(14.5)$ & $21(15.4)$ & 0.798 \\
\hline Cotinine, $n(\%)^{\mathrm{c}}$ & & & 0.149 & & & 0.001 \\
\hline $\begin{array}{l}<85 \mathrm{nmol} / \mathrm{L} \text { (light nicotine exposure) } \\
85-1,000 \mathrm{nmol} / \mathrm{L} \text { (moderate nicotine exposure) }\end{array}$ & $\begin{array}{c}1,100(80.4) \\
89(6.5)\end{array}$ & $\begin{array}{l}62(72.1) \\
8(9.3)\end{array}$ & & $\begin{array}{c}1,409(84.6) \\
131(7.9)\end{array}$ & $\begin{array}{c}144(75.4) \\
16(8.4)\end{array}$ & \\
\hline$>1,000 \mathrm{nmol} / \mathrm{L}$ (heavy nicotine exposure) & $180(13.1)$ & $16(18.6)$ & & $125(7.5)$ & $31(16.2)$ & \\
\hline Cotinine $(\mathrm{nmol} / \mathrm{L})$, median $(\mathrm{IQR})^{\mathrm{d}}$ & $0.9(9.9)$ & $1.3(586.3)$ & 0.081 & $0.4(3.4)$ & $0.9(25.9)$ & 0.001 \\
\hline \multicolumn{7}{|l|}{ Inflammation markers } \\
\hline $\mathrm{CRP}(\mu \mathrm{g} / \mathrm{mL})$, median $(\mathrm{IQR})$ & $2.2(3.4)$ & $2.3(4.9)$ & 0.441 & $2.1(3.4)$ & $2.2(3.7)$ & 0.605 \\
\hline Neopterin (nmol/L), median (IQR) & $8.6(3.3)$ & $9.6(5.2)$ & 0.003 & $8.7(3.3)$ & $8.8(4.1)$ & 0.809 \\
\hline Kynurenine/tryptophan ratio, median (IQR) & $26.1(10.1)$ & $27.5(11.1)$ & 0.172 & $26.3(10.1)$ & $26.1(11.4)$ & 0.863 \\
\hline \multicolumn{7}{|l|}{ Kynurenines } \\
\hline Tryptophan $(\mu \mathrm{mol} / \mathrm{L})$, median (IQR) & $68.2(18.3)$ & $64.3(19.6)$ & 0.117 & $62.6(17.8)$ & $61.2(17.1)$ & 0.102 \\
\hline Kynurenine $(\mu \mathrm{mol} / \mathrm{L})$, median $(\mathrm{IQR})$ & $1.8(0.6)$ & $1.8(0.7)$ & 0.913 & $1.7(0.6)$ & $1.6(0.6)$ & 0.148 \\
\hline Kynurenic acid (nmol/L), median (IQR) & $54.6(27.3)$ & $53.5(38.8)$ & 0.452 & $48.2(24.9)$ & $46.9(27.5)$ & 0.466 \\
\hline Anthranilic acid (nmol/L), median (IQR) & $16.7(7.3)$ & $19.0(9.3)$ & 0.028 & $15.9(6.8)$ & $16.1(7.2)$ & 0.549 \\
\hline 3-Hydroxykynurenine (nmol/L), median (IQR) & $36.2(15.3)$ & $37.0(19.7)$ & 0.480 & $35.3(15.8)$ & $35.1(17.1)$ & 0.386 \\
\hline Xanthurenic acid (nmol/L), median (IQR) & $16.6(11.0)$ & $16.3(10.3)$ & 0.515 & $14.1(9.1)$ & $13.4(8.4)$ & 0.054 \\
\hline 3-Hydroxyanthranilic acid (nmol/L), median (IQR) & $36.0(18.0)$ & $33.1(22.7)$ & 0.949 & $32.8(16.4)$ & $32.1(16.4)$ & 0.522 \\
\hline
\end{tabular}

$B M I$ body mass index, $C R P$ C-reactive protein, DMARD disease-modifying anti-rheumatic drug, $e G F R$ estimated glomerular filtration rate, $I Q R$ interquartile range, $N S A I D$ non-steroidal anti-inflammatory drug, $N A$ not applicable, $S D$ standard deviation

${ }^{\text {a }}$ Total numbers may vary between variables due to missing data

${ }^{\mathrm{b}}$ Groups with and without hip fracture compared within each sex by independent samples $t$ test (continuous data) or the exact chi-square test (categorical data)

${ }^{\mathrm{c}}$ Cotinine compared as categorical variable

${ }^{\mathrm{d}}$ Cotinine compared as continuous variable

to those not being in Q4 of any of the inflammatory markers $(n=1,638)$ (Fig. 2), with HR 2.51 (CI 1.59-3.98) adjusted for sex, cotinine, BMI, and eGFR ( $p$ trend $<0.001$ according to being in the highest quartile of one, two, or three markers). The distribution of participants according to any combination of the highest quartile of one, two, or all three inflammatory markers is shown in Fig. 3.

\section{Discussion}

In this study, we investigated CRP and the IFN- $\gamma$-induced inflammation markers neopterin and KTR, as well as kynurenines, in relation to risk of hip fracture. A higher risk of hip fracture among subjects in the highest compared to the lowest quartiles of neopterin, anthranilic acid, and 3- hydroxykynurenine was found, after adjustment for sex, BMI, cotinine, and renal function. These findings persisted after additional adjustment for BMD in a subgroup analysis. Further, we found that participants in the top quartiles of all three inflammatory markers (CRP, neopterin, and KTR) had a 2.5 -fold higher risk of hip fracture compared to those with no inflammatory marker in the highest quartile.

Plasma concentrations of all the kynurenines were similar to those obtained in fresh samples indicating acceptable conditions for blood sample collection and storage [27]. Levels of neopterin, tryptophan, and kynurenine were comparable to those found in other studies [22, 32], as were correlations between the inflammatory markers CRP, neopterin, and KTR [21, 22, 33].

Strengths of the study include the large size of the cohort, the long follow-up time, as well as the comprehensive 
Table 2 Risk of hip fracture by Cox proportional hazard model according to quartiles (Q1 lowest-Q4 highest) of inflammation markers and metabolites of the kynurenine pathway in 71-74 years old women and men. The Hordaland Health Study

\begin{tabular}{|c|c|c|c|c|c|c|c|}
\hline & $n$ & Model & Q1 & Q2 HR (CI) & Q3 HR (CI) & Q4 HR (CI) & $p$ trend $^{\mathrm{a}}$ \\
\hline \multirow[t]{2}{*}{ CRP } & \multirow[t]{2}{*}{3,198} & Model 1 & 1.00 (ref) & $0.91(0.65,1.29)$ & $0.95(0.68,1.34)$ & $1.08(0.77,1.50)$ & 0.638 \\
\hline & & Model 2 & 1.00 (ref) & $1.00(0.71,1.42)$ & $1.06(0.75,1.51)$ & $1.28(0.91,1.81)$ & 0.160 \\
\hline \multirow[t]{2}{*}{ Neopterin } & \multirow[t]{2}{*}{3,311} & Model 1 & 1.00 (ref) & $1.06(0.74-1.52)$ & $1.17(0.83-1.66)$ & $1.70(1.22-2.36)$ & 0.001 \\
\hline & & Model 2 & 1.00 (ref) & $1.08(0.76-1.55)$ & $1.23(0.86-1.75)$ & $1.88(1.34-2.65)$ & 0.001 \\
\hline \multirow[t]{2}{*}{ KTR } & \multirow[t]{2}{*}{3,289} & Model 1 & 1.00 (ref) & $0.80(0.57-1.12)$ & $0.85(0.61-1.19)$ & $1.10(0.80-1.51)$ & 0.515 \\
\hline & & Model 2 & 1.00 (ref) & $0.85(0.60-1.19)$ & $1.00(0.71-1.41)$ & $1.31(0.94-1.82)$ & 0.087 \\
\hline \multirow[t]{2}{*}{ Tryptophan } & \multirow[t]{2}{*}{3,311} & Model 1 & 1.00 (ref) & $0.95(0.70-1.30)$ & $0.64(0.46-0.91)$ & $0.73(0.53-1.02)$ & 0.013 \\
\hline & & Model 2 & 1.00 (ref) & $1.04(0.76-1.42)$ & $0.71(0.50-1.01)$ & $0.81(0.58-1.13)$ & 0.065 \\
\hline \multirow[t]{2}{*}{ Kynurenine } & \multirow[t]{2}{*}{3,289} & Model 1 & 1.00 (ref) & $0.78(0.56-1.09)$ & $0.87(0.62-1.20)$ & $0.94(0.68-1.31)$ & 0.863 \\
\hline & & Model 2 & 1.00 (ref) & $0.88(0.63-1.23)$ & $1.05(0.75-1.47)$ & $1.25(0.89-1.77)$ & 0.146 \\
\hline \multirow[t]{2}{*}{ Kynurenic acid } & \multirow[t]{2}{*}{3,311} & Model 1 & 1.00 (ref) & $0.72(0.52-1.01)$ & $0.70(0.50-0.97)$ & $0.91(0.66-1.25)$ & 0.500 \\
\hline & & Model 2 & 1.00 (ref) & $0.80(0.58-1.12)$ & $0.83(0.59-1.17)$ & $1.19(0.85-1.66)$ & 0.398 \\
\hline \multirow[t]{2}{*}{ Anthranilic acid } & \multirow[t]{2}{*}{3,289} & Model 1 & $1.00(\mathrm{ref})$ & $0.85(0.60-1.20)$ & $1.00(0.72-1.40)$ & $1.20(0.87-1.66)$ & 0.170 \\
\hline & & Model 2 & 1.00 (ref) & $0.96(0.67-1.36)$ & $1.24(0.87-1.75)$ & $1.48(1.06-2.08)$ & 0.009 \\
\hline \multirow[t]{2}{*}{ 3-Hydroxykynurenine } & \multirow[t]{2}{*}{3,310} & Model 1 & 1.00 (ref) & $1.14(0.82-1.59)$ & $0.90(0.63-1.27)$ & $1.29(0.93-1.79)$ & 0.30 \\
\hline & & Model 2 & 1.00 (ref) & $1.26(0.90-1.76)$ & $1.04(0.73-1.49)$ & $1.63(1.15-2.30)$ & 0.022 \\
\hline \multirow[t]{2}{*}{ Xanthurenic acid } & \multirow[t]{2}{*}{3,310} & Model 1 & 1.00 (ref) & $1.09(0.79-1.50)$ & $0.88(0.63-1.24)$ & $0.82(0.59-1.16)$ & 0.15 \\
\hline & & Model 2 & 1.00 (ref) & $1.17(0.85-1.62)$ & $1.08(0.73-1.43)$ & $1.00(0.70-1.42)$ & 0.80 \\
\hline \multirow[t]{2}{*}{ 3-Hydroxyanthranilic acid } & \multirow[t]{2}{*}{3,310} & Model 1 & $1.00(\mathrm{ref})$ & $0.82(0.59-1.14)$ & $0.73(0.52-1.02)$ & $0.87(0.63-1.20)$ & 0.31 \\
\hline & & Model 2 & 1.00 (ref) & $0.94(0.68-1.31)$ & $0.87(0.62-1.22)$ & $1.10(0.79-1.53)$ & 0.73 \\
\hline
\end{tabular}

Model 1: adjusted for sex

Model 2: adjusted for sex, body mass index, cotinine, eGFR (estimated glomerular filtration rate over/below $60 \mathrm{~mL} / \mathrm{min}$ )

$C I 95 \%$ confidence interval, CRP C-reactive protein, HR hazard ratio, KTR kynurenine/tryptophan ratio, $Q 1-Q 4$ quartiles 1 to 4

${ }^{\mathrm{a}}$ Across quartiles

laboratory analyses performed at the same laboratory. Data on medication may have been insufficient as participants were only asked about medications taken the previous day. Concentrations of biomarkers and data on potential confounders were obtained at baseline and not repeated during follow-up. However, the biomarkers have sufficient reproducibility (intraclass correlation coefficient over $2-3.5$ years in the range $0.5-0.7)$ to allow one-exposure assessment of biomarker status [28].

KTR and the kynurenines are earlier found to be associated with BMI [34], smoking [34, 35], and renal function [23, 34]. These factors are confounders in the relation between kynurenines and osteoporosis/fracture risk [36-38] and were therefore adjusted for.

CRP levels were not significantly associated with risk of hip fractures in the present study. This was somewhat unexpected, as an association between CRP and low-trauma fractures has previously been reported [5-7, 9]. To our knowledge, risk of hip fractures separately in relation to CRP has only been investigated in one study [39], demonstrating no significant association.

We found that the IFN- $\gamma$-mediated inflammation marker neopterin was associated with an increased risk of hip fracture.
A higher IFN- $\gamma$ production in peripheral blood mononuclear cells has been reported for postmenopausal women with vertebral fractures, compared to controls [13], and experimental studies have indicated a role of IFN- $\gamma$ in postmenopausal bone loss [40]. However, we are aware of no previous studies on plasma neopterin and fracture risk. Due to the complexity of the immunologic pathways involved in inflammation, combining different markers may better reflect overall activation of the immune system than one single inflammatory marker. An enhanced prediction of fracture risk by combining inflammatory markers has been reported for other studies as well $[3,4]$.

The observed association between inflammation assessed by neopterin and risk of fracture was independent of BMD. This is in agreement with earlier studies [4-7, 9], suggesting an impact of inflammation on bone microarchitecture and bone strength $[5,8]$, or the finding could possibly be explained by other factors such as reduced muscle strength, impaired balance, or impaired nutritional status.

In the present study, anthranilic acid and 3hydroxykynurenine were associated with an increased risk of hip fracture. We are not aware of previous studies on kynurenines in relation to fracture risk, but the finding is in accordance with one other study describing increased levels 
Fig. 2 Kaplan-Meier survival curves for time to hip fracture in 3,178 men and women (71-74 years at inclusion), stratified on subjects in the highest quartiles of none $(n=1,638)$, one $(n=879)$, two $(n=490)$, or three $(n=171)$ inflammation markers (CRP, neopterin, kynurenine/tryptophan ratio). The Hordaland Health study

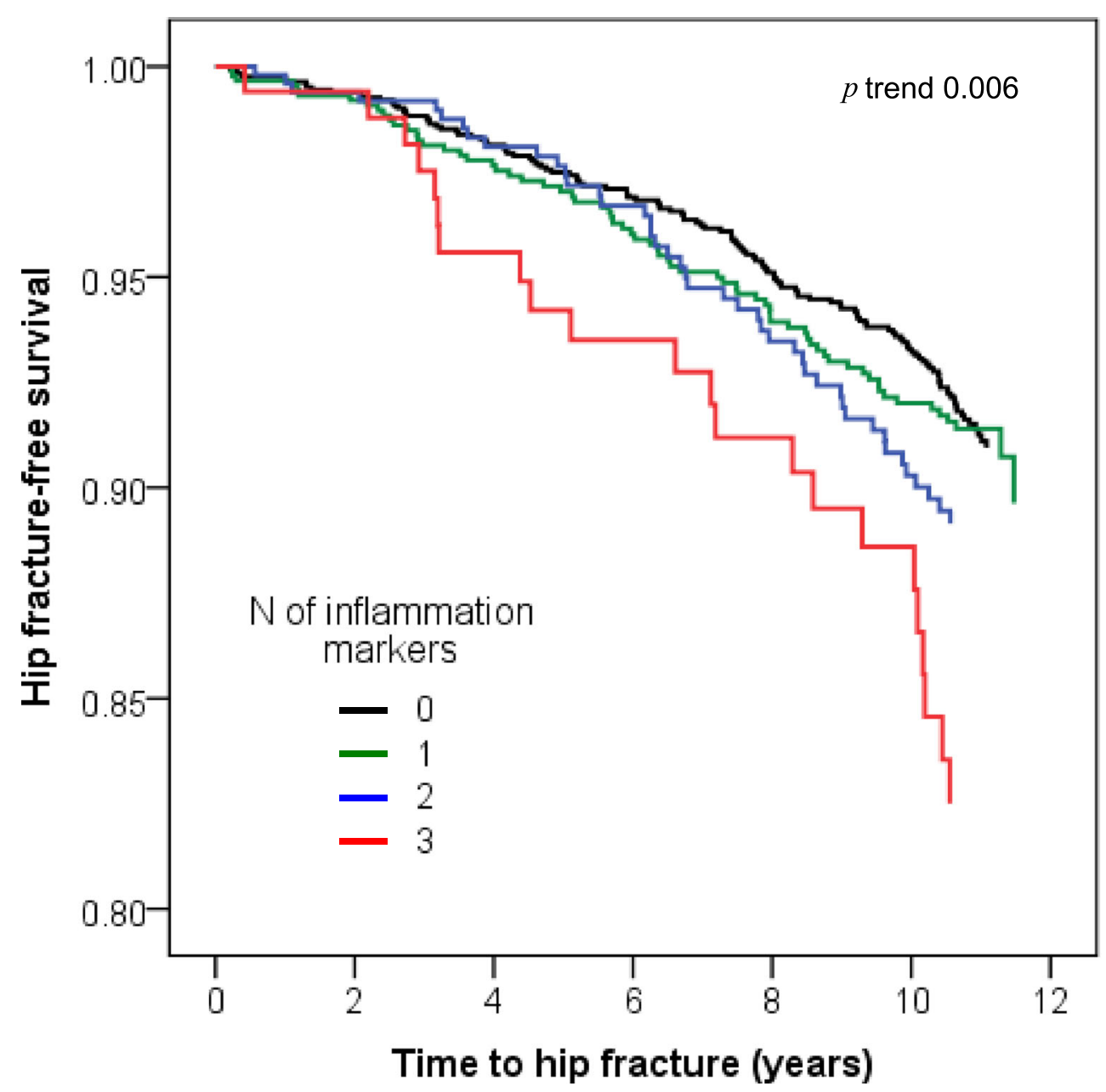

Our knowledge of the immune system has evolved from the idea of a mere protector against invading organisms to an of anthranilic acid in osteoporotic patients compared to controls [41].
Fig. 3 Venn diagram showing the distribution of participants in the Hordaland Health Study according to inflammatory status assessed as any combination of inflammatory markers in the upper quartile of each marker. Of the 3,178 participants with measurements of all three inflammatory markers, 1,638 $(51.5 \%)$ persons were not in the highest quartile of any of the inflammatory markers. The correct proportional overlap between the inflammatory markers is shown, and numbers show percentages of the total cohort

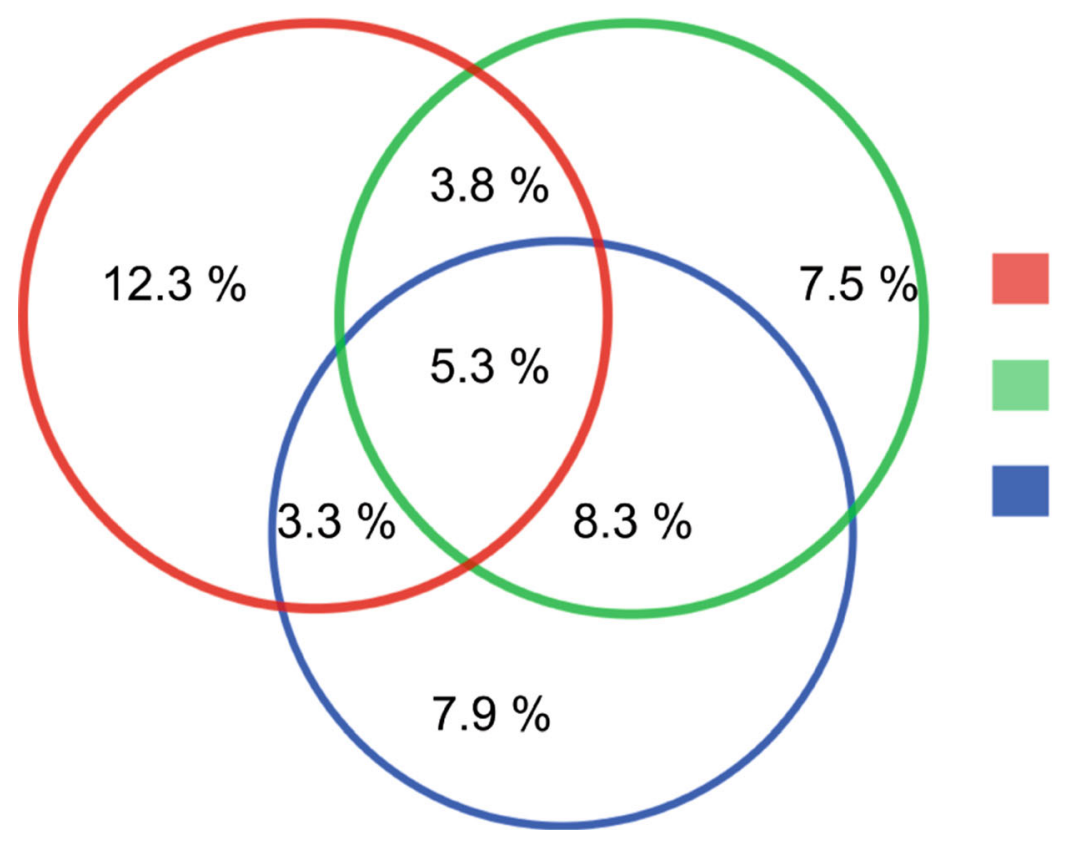

CRP

Neopterin

KTR 
increasing understanding of its cruciate role in physiological processes, including differentiation and stimulation of bone cells [1]. CRP release is mainly elicited by interleukin-6 (IL-6) [42], one of several cytokines inducing release of RANKL [1], the main stimulator of bone degradation. IFN- $\gamma$ has been found to stimulate osteoclast formation in states of immune activation through $\mathrm{T}$ cell RANK signaling [12]. T cell RANKL expression has, however, not been found as an important stimulator of bone resorption in non-inflammatory conditions [43]. In contrast, murine studies have shown that IFN- $\gamma$ is essential for development of normal bone structure under physiological conditions [11]. IFN- $\gamma$ also reduces bone resorption in vitro by inhibiting the ability of 1,25 dihydroxyvitamin D3, parathyroid hormone, and IL-1 to stimulate the formation of osteoclast-like cells [1]. Higher expression of IFN- $\gamma$-related genes in human hip bone samples from osteoarthritic compared with osteoporotic patients has been reported [16], which is not in agreement with our earlier and present findings indicating an association between IFN- $\gamma$-stimulated inflammation and increased risk of low BMD and hip fracture [24]. This may illustrate a difference in local and systemic effects.

3-Hydroxykynurenine has both pro- and anti-oxidative properties [20,44] and was associated with risk of hip fracture in the present study. An increase in reactive oxygen species has been linked to higher bone resorption [45]. The association between 3-hydroxykynurenine and an increased risk of hip fracture in the present study may also be related to a positive association between 3-hydroxykynurenine and inflammatory markers [33].

In this study, we found that the inflammation marker neopterin was positively associated with risk of hip fracture, while CRP and KTR were not. This may possibly reflect a greater impact of IFN- $\gamma$-mediated inflammation on fracture risk than components of the innate immune system as measured by CRP. Further, high levels of anthranilic acid and 3-hydroxykynurenine were also associated with increased risk of hip fracture. Although these findings may suggest an association between INF- $\gamma-$ mediated inflammation and risk of hip fractures, additional studies are required to explore the role of IDO and kynurenines in bone metabolism.

Acknowledgments Donations from the Norwegian Rheumatism Association funded a part of the biochemical analyses.

\section{Conflicts of interest None.}

Open Access This article is distributed under the terms of the Creative Commons Attribution Noncommercial License which permits any noncommercial use, distribution, and reproduction in any medium, provided the original author(s) and the source are credited.

\section{References}

1. Lorenzo J, Horowitz M, Choi Y (2008) Osteoimmunology: interactions of the bone and immune system. Endocr Rev 29:403-440

2. Koh JM, Khang YH, Jung CH, Bae S, Kim DJ, Chung YE, Kim GS (2005) Higher circulating hsCRP levels are associated with lower bone mineral density in healthy pre- and postmenopausal women: evidence for a link between systemic inflammation and osteoporosis. Osteoporos Int 16: 1263-1271

3. Barbour KE, Boudreau R, Danielson ME, Youk AO, WactawskiWende J, Greep NC, LaCroix AZ, Jackson RD, Wallace RB, Bauer DC, Allison MA, Cauley JA (2012) Inflammatory markers and the risk of hip fracture: the Women's Health Initiative. J Bone Miner Res 27:1167-1176

4. Cauley JA, Danielson ME, Boudreau RM, Forrest KY, Zmuda JM, Pahor M, Tylavsky FA, Cummings SR, Harris TB, Newman AB (2007) Inflammatory markers and incident fracture risk in older men and women: the Health Aging and Body Composition Study. J Bone Miner Res 22:1088-1095

5. Ishii S, Cauley JA, Greendale GA, Crandall CJ, Danielson ME, Ouchi Y, Karlamangla AS (2013) C-reactive protein, bone strength, and nine-year fracture risk: data from the Study of Women's Health Across the Nation (SWAN). J Bone Miner Res 28:1688-1698

6. Nakamura K, Saito T, Kobayashi R, Oshiki R, Oyama M, Nishiwaki T, Nashimoto M, Tsuchiya Y (2011) C-reactive protein predicts incident fracture in community-dwelling elderly Japanese women: the Muramatsu study. Osteoporos Int 22:2145-2150

7. Pasco JA, Kotowicz MA, Henry MJ, Nicholson GC, Spilsbury HJ, Box JD, Schneider HG (2006) High-sensitivity C-reactive protein and fracture risk in elderly women. JAMA 296:1353-1355

8. Rolland T, Boutroy S, Vilayphiou N, Blaizot S, Chapurlat R, Szulc P (2012) Poor trabecular microarchitecture at the distal radius in older men with increased concentration of high-sensitivity C-reactive protein - the STRAMBO study. Calcif Tissue Int 90:496-506

9. Schett G, Kiechl S, Weger S, Pederiva A, Mayr A, Petrangeli M, Oberhollenzer F, Lorenzini R, Redlich K, Axmann R, Zwerina J, Willeit J (2006) High-sensitivity C-reactive protein and risk of nontraumatic fractures in the Bruneck study. Arch Intern Med 166: 2495-2501

10. Hoffmann G, Wirleitner B, Fuchs D (2003) Potential role of immune system activation-associated production of neopterin derivatives in humans. Inflamm Res 52:313-321

11. Duque G, Huang DC, Dion N, Macoritto M, Rivas D, Li W, Yang XF, Li J, Lian J, Marino FT, Barralet J, Lascau V, Deschenes C, Ste-Marie LG, Kremer R (2011) Interferon-gamma plays a role in bone formation in vivo and rescues osteoporosis in ovariectomized mice. J Bone Miner Res 26:1472-1483

12. Gao Y, Grassi F, Ryan MR, Terauchi M, Page K, Yang X, Weitzmann MN, Pacifici R (2007) IFN-gamma stimulates osteoclast formation and bone loss in vivo via antigen-driven $\mathrm{T}$ cell activation. $\mathrm{J}$ Clin Invest 117:122-132

13. Breuil V, Ticchioni M, Testa J, Roux CH, Ferrari P, Breittmayer JP, Albert-Sabonnadiere C, Durant J, De Perreti F, Bernard A, EullerZiegler L, Carle GF (2010) Immune changes in post-menopausal osteoporosis: the Immunos study. Osteoporos Int 21:805-814

14. Pietschmann P, Grisar J, Thien R, Willheim M, Kerschan-Schindl K, Preisinger E, Peterlik M (2001) Immune phenotype and intracellular cytokine production of peripheral blood mononuclear cells from postmenopausal patients with osteoporotic fractures. Exp Gerontol 36:1749-1759

15. Swanberg M, McGuigan FE, Ivaska KK, Gerdhem P, Akesson K (2012) Polymorphisms in the inflammatory genes CIITA, CLEC16A and IFNG influence BMD, bone loss and fracture in elderly women. PloS One 7:e47964 
16. Zupan J, Komadina R, Marc J (2012) The relationship between osteoclastogenic and anti-osteoclastogenic pro-inflammatory cytokines differs in human osteoporotic and osteoarthritic bone tissues. J Biomed Sci 19:28

17. Huber C, Batchelor JR, Fuchs D, Hausen A, Lang A, Niederwieser D, Reibnegger G, Swetly P, Troppmair J, Wachter H (1984) Immune response-associated production of neopterin. Release from macrophages primarily under control of interferon-gamma J Exp Med 160: 310-316

18. Mandi Y, Vecsei L (2012) The kynurenine system and immunoregulation. J Neural Transm 119:197-209

19. Munn DH, Sharma MD, Lee JR, Jhaver KG, Johnson TS, Keskin DB, Marshall B, Chandler P, Antonia SJ, Burgess R, Slingluff CL Jr, Mellor AL (2002) Potential regulatory function of human dendritic cells expressing indoleamine 2,3-dioxygenase. Science 297:18671870

20. Giles GI, Collins CA, Stone TW, Jacob C (2003) Electrochemical and in vitro evaluation of the redox-properties of kynurenine species. Biochem Biophys Res Commun 300:719-724

21. Capuron L, Schroecksnadel S, Feart C, Aubert A, Higueret D, Barberger-Gateau P, Laye S, Fuchs D (2011) Chronic low-grade inflammation in elderly persons is associated with altered tryptophan and tyrosine metabolism: role in neuropsychiatric symptoms. Biol Psychiatry 70:175-182

22. Pedersen ER, Midttun O, Ueland PM, Schartum-Hansen H, Seifert R, Igland J, Nordrehaug JE, Ebbing M, Svingen G, Bleie O, Berge R, Nygard O (2011) Systemic markers of interferon-gamma-mediated immune activation and long-term prognosis in patients with stable coronary artery disease. Arterioscler Thromb Vasc Biol 31:698-704

23. Schefold JC, Zeden JP, Fotopoulou C, von Haehling S, Pschowski R, Hasper D, Volk HD, Schuett C, Reinke P (2009) Increased indoleamine 2,3-dioxygenase (IDO) activity and elevated serum levels of tryptophan catabolites in patients with chronic kidney disease: a possible link between chronic inflammation and uraemic symptoms. Nephrol Dial Transplant 24:1901-1908

24. Apalset EM, Gjesdal CG, Ueland PM, Midttun O, Ulvik A, Eide GE, Meyer K, Tell GS (2014) Interferon gamma (IFNgamma) mediated inflammation and the kynurenine pathway in relation to bone mineral density: The Hordaland Health Study. Clin Exp Immunol. doi:10. 1111/cei. 12288

25. Konstantinova SV, Tell GS, Vollset SE, Ulvik A, Drevon CA, Ueland PM (2008) Dietary patterns, food groups, and nutrients as predictors of plasma choline and betaine in middle-aged and elderly men and women. Am J Clin Nutr 88:1663-1669

26. Midttun O, Hustad S, Ueland PM (2009) Quantitative profiling of biomarkers related to B-vitamin status, tryptophan metabolism and inflammation in human plasma by liquid chromatography/tandem mass spectrometry. Rapid Commun Mass Spectrom 23:1371-1379

27. Hustad S, Eussen S, Midttun O, Ulvik A, van de Kant PM, Morkrid L, Gislefoss R, Ueland PM (2012) Kinetic modeling of storage effects on biomarkers related to $\mathrm{B}$ vitamin status and one-carbon metabolism. Clin Chem 58:402-410

28. Midttun O, Townsend MK, Nygard O, Tworoger SS, Brennan P, Johansson M, Ueland PM (2014) Most blood biomarkers related to vitamin status, one-carbon metabolism, and the kynurenine pathway show adequate preanalytical stability and within-person reproducibility to allow assessment of exposure or nutritional status in healthy women and cardiovascular patients. J Nutr. doi:10.3945/jn.113. 189738

29. Gjesdal CG, Vollset SE, Ueland PM, Refsum H, Meyer HE, Tell GS (2007) Plasma homocysteine, folate, and vitamin B 12 and the risk of hip fracture: the Hordaland homocysteine study. J Bone Miner Res 22:747-756
30. Lofthus CM, Osnes EK, Falch JA, Kaastad TS, Kristiansen IS, Nordsletten L, Stensvold I, Meyer HE (2001) Epidemiology of hip fractures in Oslo, Norway. Bone 29:413-418

31. Levey AS, Bosch JP, Lewis JB, Greene T, Rogers N, Roth D (1999) A more accurate method to estimate glomerular filtration rate from serum creatinine: a new prediction equation. Modification of Diet in Renal Disease Study Group. Ann Intern Med 130:461-470

32. Frick B, Schroecksnadel K, Neurauter G, Leblhuber F, Fuchs D (2004) Increasing production of homocysteine and neopterin and degradation of tryptophan with older age. Clin Biochem 37:684-687

33. Midttun O, Ulvik A, Ringdal Pedersen E, Ebbing M, Bleie O, Schartum-Hansen H, Nilsen RM, Nygard O, Ueland PM (2011) Low plasma vitamin B-6 status affects metabolism through the kynurenine pathway in cardiovascular patients with systemic inflammation. J Nutr 141:611-617

34. Theofylaktopoulou D, Midttun O, Ulvik A, Ueland PM, Tell GS, Vollset SE, Nygard O, Eussen SJ (2013) A community-based study on determinants of circulating markers of cellular immune activation and kynurenines: the Hordaland Health Study. Clin Exp Immunol $173: 121-130$

35. Pertovaara M, Heliovaara M, Raitala A, Oja SS, Knekt P, Hurme M (2006) The activity of the immunoregulatory enzyme indoleamine 2, 3-dioxygenase is decreased in smokers. Clin Exp Immunol 145:469 473

36. Kanis JA, McCloskey EV (1998) Risk factors in osteoporosis Maturitas 30:229-233

37. Meyer HE, Tverdal A, Falch JA (1993) Risk factors for hip fracture in middle-aged Norwegian women and men. Am J Epidemiol 137: $1203-1211$

38. Papaioannou A, Joseph L, Ioannidis G, Berger C, Anastassiades T, Brown JP, Hanley DA, Hopman W, Josse RG, Kirkland S, Murray TM, Olszynski WP, Pickard L, Prior JC, Siminoski K, Adachi JD (2005) Risk factors associated with incident clinical vertebral and nonvertebral fractures in postmenopausal women: the Canadian Multicentre Osteoporosis Study (CaMos). Osteoporos Int 16:568578

39. Cauley J, Cloonan YK, Danielson M, Ensrud K, Fink H, Orwoll E, Boudreau R (2011) Inflammatory markers and the risk of hip and spine fractures in older men: MrOs. J Bone Miner Res 26(Suppl 1): S1

40. Cenci S, Toraldo G, Weitzmann MN, Roggia C, Gao Y, Qian WP, Sierra O, Pacifici R (2003) Estrogen deficiency induces bone loss by increasing $\mathrm{T}$ cell proliferation and lifespan through IFN-gammainduced class II transactivator. Proc Natl Acad Sci U S A 100: 10405-10410

41. Forrest CM, Mackay GM, Oxford L, Stoy N, Stone TW, Darlington LG (2006) Kynurenine pathway metabolism in patients with osteoporosis after 2 years of drug treatment. Clin Exp Pharmacol Physiol 33:1078-1087

42. Schultz DR, Arnold PI (1990) Properties of four acute phase proteins: C-reactive protein, serum amyloid A protein, alpha 1-acid glycoprotein, and fibrinogen. Semin Arthritis Rheum 20:129-147

43. Nakashima T, Hayashi M, Fukunaga T, Kurata K, Oh-Hora M, Feng JQ, Bonewald LF, Kodama T, Wutz A, Wagner EF, Penninger JM, Takayanagi H (2011) Evidence for osteocyte regulation of bone homeostasis through RANKL expression. Nat Med 17:1231-1234

44. Leipnitz G, Schumacher C, Dalcin KB, Scussiato K, Solano A, Funchal C, Dutra-Filho CS, Wyse AT, Wannmacher CM, Latini A, Wajner M (2007) In vitro evidence for an antioxidant role of 3hydroxykynurenine and 3-hydroxyanthranilic acid in the brain. Neurochem Int 50:83-94

45. Almeida M (2011) Unraveling the role of FoxOs in bone-insights from mouse models. Bone 49:319-327 